\title{
Prevalence and Correlates of Suicide Attempts in High-Risk Populations: A Cohort study among patients receiving opioid Agonist Therapy in Norway
}

Jørn Henrik Vold ( $\boldsymbol{D}$ jorn.vold@uib.no)

Department of Addiction Medicine, Haukeland University Hospital, Bergen

Else-Marie Løberg

Department of Addiction Medicine, Haukeland University Hospital, Bergen

Christer F. Aas

Department of Addiction Medicine, Haukeland University Hospital, Bergen

Jan Alexander Steier

Department of Psychiatry, Haukeland University Hospital, Bergen

Kjell Arne Johansson

Department of Addiction Medicine, Haukeland University Hospital, Bergen

Lars Thore Fadnes

Department of Addiction Medicine, Haukeland University Hospital, Bergen

\section{Research Article}

Keywords: substance-related disorders, suicide attempts, opiate substitution treatment, injecting substance use

Posted Date: October 21st, 2021

DOI: https://doi.org/10.21203/rs.3.rs-960846/v1

License: (c) (i) This work is licensed under a Creative Commons Attribution 4.0 International License. Read Full License 


\section{Abstract \\ Background}

Death by suicide in patients enrolled in opioid agonist therapy (OAT) is a major clinical concern. However, little knowledge exists regarding suicide attempts in this patient group. This study presents the lifetime prevalence of suicide attempts and the associations between suicide attempts and clinical and sociodemographic variables such as education, sex, early onset of substance use ( $<13$ years of age), substance use patterns, and injecting substance use among patients receiving OAT.

\section{Methods}

We used data from a cohort of OAT patients in Norway obtained from a health assessment of selfreported suicide attempts and sociodemographic and clinical factors. A total of 595 patients receiving OAT were assessed from 2016 to 2020. A binary logistic regression analysis was performed and reported with an unadjusted odds ratio and $95 \%$ confidence intervals (OR). The purpose of this assessment was to analyze associations between suicide attempts and substance use patterns as well as the injection of substances during the 30 days leading up to the health assessment. A negative binomial regression analysis with an incidence rate ratio and $95 \%$ confidence intervals (IRR) was performed to investigate sex, education, early onset of substance use, and the number of suicide attempts.

\section{Results}

Forty-one percent of the OAT patients had attempted to die by suicide at least once during their lifetime. An early onset of substance use was strongly associated with the suicide attempts (IRR: 1.7, 1.3-2.2). No significant association was found between suicide attempts and sex (IRR: 1.2, 0.9-1.6) or education (IRR: $0.6,0.2-2.1)$. Likewise, no association was identified between suicide attempts and injecting substance use (OR: 0.9, 0.6-1.3), nor using alcohol (OR: 0.9, 0.7-1.3), amphetamines (OR: 1.0, 0.7-1.3), benzodiazepines (OR: 1.0, 0.7-1.4), cannabis (OR: 1.2, 0.9-1.7), cocaine (OR: $1.3,0.6-3.0)$, or opioids (OR: 1.4, 0.9-2.0).

\section{Conclusion}

The lifetime prevalence of suicide attempts was alarmingly high in the OAT population. An early onset of substance use seemed to be an important risk factor for suicide attempts. Multiple actions are needed to prevent premature deaths by suicide in this high-risk population, and these include: health policies to prevent suicides, research on efficacy of suicide prevention interventions and clinical precision in management of patients with a high risk of suicide. 


\section{Background}

Nearly two out of five patients entering substance use disorder (SUD) treatment have attempted suicide during their lifetime [1-3]. This is, in part, attributable to a chaotic life situation consisting of unstable housing and living conditions, extensive substance use, violence, physical and mental traumatic events, and comorbid mental health disorders [4, 5]. In 2020, the European Union's Drug Strategy for 2020-2025 aimed to improve personal mental health and reduce premature deaths in European countries for marginalized SUD patients [6]. As a part of this strategy, the European Union called for better characterization of mental health in various SUD populations in order to reduce barriers to treatment and facilitate targeted treatment. Suicide attempts may lead to suicide and they are a major clinical concern in this patient population [7]. The literature is scarce on the prevalence of suicide attempts among SUD populations, and there is a substantial lack of significance attributed to associated risk factors [8].

Opioid agonist therapy (OAT) is a well-known treatment approach used by SUD patients to recover from severe opioid dependence [9]. Although OAT may improve mental health symptoms $[10,11]$ and reduce opioid-related deaths and illegal opioid use [12-15], OAT patients usually suffer from mental comorbidities strongly associated with suicide [16]. Suicide is the second leading limiting factor in OAT patient prognosis; the overdose-related accident is the most common cause [17]. Globally, nearly one out of five heroin users entering OAT have attempted suicide ever [16]. Additionally, heroin users that inject substances are 14 times more likely to die from suicide than the general population [18]. This corresponds to a suicide lifetime prevalence of up to $35 \%$ among this population [19].

Mental health disorders in general--particularly affective and borderline personality disorders--are significantly associated with suicide attempts and death by suicide [20-23]. The lifetime prevalence of depressive symptoms exceeds $60 \%$ in the OAT population [24], and $13-34 \%$ report current major depressive symptoms [25-27]. Otherwise, the lifetime prevalence of borderline personality disorder ranges widely from $7-47 \%$ in observational studies $[26,28]$. This places OAT patients at particular risk of attempting suicide. Furthermore, the impact of other potential suicide attempt risk factors--such as the early onset of substance use, types of substance use, injecting substance use, and education--remain unclear $[29,30]$.

Thus, the primary objective of the present study is to estimate the lifetime prevalence of suicide attempts among patients with severe opioid dependence who were enrolled in opioid agonist therapy (OAT). The secondary objective is to investigate the association between suicide attempts and potential risk factors. More specifically, we will:

1. estimate the lifetime prevalence of suicide attempts

2. investigate the associations between sex, level of education, early onset of substance use, and suicide attempts.

3. evaluate the associations between suicide attempts and injecting substance use and consuming alcohol, amphetamines, benzodiazepines, cannabis, cocaine, and opioids. 


\section{Methods}

\subsection{Data source}

We used data from a cohort nested in the INTRO-HCV study in Bergen and Stavanger, Norway [31]. Data were collected from May 2016 to July 2020, and patients were recruited from OAT outpatient clinics in the aforementioned cities.

\subsection{Data collections}

During a health assessment, the included patients were assessed regarding their suicide attempts, current substance use and injecting substance use, and other sociodemographic and clinical data. The data were stored in a health register using electronic data collection software (Checkware) under the supervision of trained research nurses. The clinical data--including level of education, severe infectious diseases (hepatitis $C$ virus, hepatitis $B$ virus, and human immunodeficiency virus infections), suicide attempts, injecting substance use, and substance use-- were collected from the electronic medical record. A total of 595 OAT patients were recruited during the study period. The mean time that patients had spent in OAT was eight years with a standard deviation (SD) of five years.

\subsection{Definition of study variables}

A suicide attempt was defined as any self-reported attempted suicide during a lifetime. The suicide variable was divided into five groups: zero, one, two, three, or four or more suicide attempts. We defined 'receiving OAT' according to the OAT medication (buprenorphine or methadone) stated during the health assessment. The level of education was defined as the highest level of education completed, and this was categorized into five classes: "not completed primary school", "completed primary school (nine years)", "completed high school (12 years)", "completed three years or less of college or university", and "completed more than three years of college or university." We set "injecting substance use" as having injected at least once during the 30 days leading up to the health assessment. Similarly, substance use was divided into six classes: "alcohol", "amphetamines", "benzodiazepines", "cannabis", "cocaine", and "opioids", according to the use during the past 30 days. The early onset of substance use was defined categorically as those using any kinds of substances--including amphetamines, alcohol, benzodiazepines, cannabis, cocaine, or opioids--before the age of $13(<13)$. Thirteen years of age represented the mean age for the onset of substance use in the study sample. Moreover, we assessed the extent of severe infectious diseases as markers of the study sample's comorbidities. This was done by drawing blood samples of chronic infectious diseases during the health assessment. Current infections were defined as detecting hepatitis $C$ virus RNA by polymerase chain reaction (hepatitis $C$ virus infection), hepatitis B virus surface antigens (hepatitis B virus infection), or human immunodeficiency virus antigens/antibodies (human immunodeficiency virus infection). Blood samples were analyzed at the Department of Laboratory Medicine at Haukeland University Hospital in Bergen, Norway, and the Department of Medical Biochemistry and Microbiology at Stavanger University Hospital in Stavanger, Norway (accredited by ISO standard 15189). 


\subsection{Statistical analyses}

We used Stata/SE 17.0 (StataCorp, TX, USA) for the descriptive and regression model analyses. Microsoft Excel was used to create a bar chart and IBM SPSS version 26.0 was used to expectation-maximization imputation. Unless otherwise stated, the threshold for statistical significance was set to $P<0.05$ for all analyses.

We dealt with any missing values concerning the potential suicide attempt risk factors-- including the variables of types of substances used, early onset of substance use, and injecting substance use--as 'missing at random' when running expectation-maximization imputation. We identified missing values in $10 \%$ in these factors and all were replaced with estimated values by imputation.

We performed a logistic regression analysis reported with an odds ratio and $95 \%$ confidence intervals (OR) to investigate the unadjusted association between suicide attempts [binary exposure variable (yes/no)] and injecting substance use, as well as the use of amphetamines, benzodiazepines, cocaine, cannabis, and opioids [binary outcome variables (yes/no)]. Furthermore, a negative binomial regression analysis reported with an incidence rate ratio and $95 \%$ confidence intervals (IRR) was performed to investigate the unadjusted association between gender, level of education, and the early onset of substance use (categorical exposure variables) and the number of suicide attempts (numeric outcome variable). If the number of suicide attempts exceeded four, it was handled as four suicide attempts in the analysis.

\subsection{Ethics approval and consent to participate}

The study was reviewed and approved by the Regional Ethical Committee for Health Research West, Norway (REK Vest 2017/51). Each patient provided written informed consent prior to enrolling in the study.

\section{Results}

\subsection{Patients' characteristics}

A total of $71 \%$ of the study sample participants were males, and the mean age was 44 years (SD: 10 years) (Table 1). Five percent of the participants had not completed primary school, and $45 \%$ had primary school listed as their highest level of education. Seventy-nine percent had consumed at least one substance, and $30 \%$ had injected substances during the 30 days leading up to the health assessment. The mean onset age for substance use was 13 years (SD: 2 years).

\subsection{Lifetime prevalence of suicide attempts}

A total of $41 \%$ of the study sample participants had attempted suicide at least once (Figure 1), with prevalence estimates of $46 \%$ among females and $39 \%$ among males. Additionally, $10 \%$ reported four or 
more suicide attempts during their lifetime.

\subsection{Unadjusted associations between suicide attempts and substance use, as well as injecting substance use}

No association was found between suicide attempts (as an exposure factor) and injecting substance use (OR: 0.9, 0.6-1.3), as well as using substances: alcohol (OR: 0.9, 0.7-1.3), amphetamines (OR: 1.0, 0.71.3), benzodiazepines (OR: 1.0, 0.7-1.4), cannabis (OR: 1.2, 0.9-1.7), cocaine (OR: 1.3, 0.6-3.0), or opioids (OR: 1.4, 0.9-2.0) (Table 2). Although insignificant, there was a tendency for more consumption of opioids and cannabis among patients who attempted suicide.

\subsection{Unadjusted associations between early onset of substance use, level of education, sex, and suicide attempts}

The onset of substance use under 13 years of age (as an exposure factor) was strongly associated with suicide attempts (IRR: 1.7, 1.3-2.2) (Table 3). However, no significant association was found between sex (as an exposure factor) and suicide attempts (IRR: 1.2, 0.9-1.6). Likewise, not completing primary school and completing primary school (IRR: $0.8,0.4-1.5$ ), high school (IRR: $0.8,0.4-1.5$ ), three years or less of college or university (IRR: 1.0, 0.5-2.1), or more than 3 years of college or university (IRR: $0.6,0.2-2.1$ ) (as exposure factors) were not associated with suicide attempts.

\section{Discussion}

The present study showed that two out of five patients had attempted to die by suicide during their lifetime; females tended to have slightly higher rates than males. Being introduced to substances before the age of 13 was strongly associated with suicide attempts when compared to being introduced after this age. Nevertheless, completing primary school or higher education was not associated with suicide attempts when compared to non-completion. Suicide attempts were not significantly associated with the current use of substances or the injection of substances. However, there was a trend towards more consumption of opioids and cannabis among patients who attempted suicide.

The lifetime prevalence of suicide attempts in the general population is around $4 \%$ [32], substantially lower than observed in this high-risk OAT population. Despite the very high prevalence of suicide attempts among patients receiving OAT, the suicide attempt prevalence is unfortunately in line with or slightly exceeds the suicide attempt prevalence of several severe mental disorders, such as bipolar disorder (34\%) [33], schizophrenia $(25 \%-50 \%)$ [34, 35], and borderline personality disorder $(60 \%-70 \%)$ [36]. Furthermore, the impact of comorbid mental disorders on suicide attempts among SUD patients was significant, suggesting an even higher risk of suicide attempts for OAT patients with comorbid mental disorders than those without mental comorbidities [37-40]. In Norway, where 15\% of OAT patients report current depressive symptoms and 7\% have delusions [41], these underlying mental symptoms are likely associated with the high prevalence of suicide attempts in this population. 
The early onset of substance use, in the present study--meaning substance use before reaching the age of 13--was strongly associated with suicide attempts in the OAT population. Being exposed to substance use at an early age is usually a significant risk factor for extensive and injecting substance use and relapsing to substance use after SUD treatment [42-44]. Additionally, patients with early initiation of substances are more likely to become pregnant at an earlier age, become unemployed, commit crime, and meet the criteria for mental disorders (i.e., mainly severe personality disorders) [45-47]. This spectrum of medical and psychosocial risk factors in SUD populations often leads to chaotic life situations consisting of hopelessness, impulsive-aggressive personality traits, and self-harm associated with suicide attempts $[48,49]$. In the present study sample, where many OAT patients lived chaotically and suffered from a history of polysubstance use, several of these risk factors were found. This might be a significant reason for our findings.

To our knowledge, no studies have evaluated suicide attempt associations with the types of substances used in the OAT population. However, the types of substance dependencies are important risk factors found in global suicide predictions [50]. While alcohol dependence is the leading factor of suicide among SUD patients [50,51], opioid dependence--following the current opioid epidemic in the US--is a likely cause of the increasing suicide rates seen over the past decade [52]. This may be attributable in part to more comorbidities in the population, of which polysubstance use--particularly opioids and benzodiazepines--is an essential contributor $[53,54]$. However, in the Norwegian OAT population, where polysubstance use is high and remains substantially unchanged over time, the incidence rate of premature deaths-- including suicide, injuries, and murder--has remained steady in recent years [41]. This may support our findings, particularly those showing no associations between suicide attempts and the type of current substances used.

\section{Strengths And Limitations}

A major strength of this study is its relatively large sample size of 595 patients receiving OAT who are typically difficult reach in health-care. However, one important limitation of the present study is the data structure with few data points: this limits possible assessment of factors, as they can only be assumed to be either prior to or after suicide attempts. This made it difficult to make a causal inference model. Thus, we opted to present crude associations for some key factors where we had underlying hypotheses. To some degree, this may also reduce the generalizability of the results to other settings or groups that do not receive OAT. Another limitation of this study can be found in the self-reported data aspect. The individuals' definition of suicide attempts may vary significantly, and their abilities to remember suicide attempts introduce recall bias. Similarly, recognizing the consumption of different types of substances and their frequency of use might be difficult.

\section{Conclusion}

Forty-one percent of patients enrolled in OAT had a history of suicide attempts. Early onset of substance use was associated with suicide attempts, while no significant association was found between suicide 
attempts and the types of substances used or the injection of substances. In this population, there is an urgent need for further understanding of the issues concerning suicide behavior and prevention.

\section{Abbreviations}

OR

Odds Ratio

IRR

Incidence Rate Risk

OAT

Opioid Agonist Therapy

SD

Standard Deviation

SUD

Substance Use Disorder

\section{Declarations}

\section{Ethics approval and consent to participate}

The study has been reviewed and approved in accordance with the relevant guidelines and regulations by the Regional Ethical Committee for Health Research (REC) West, Norway (reference number: 2017/51/REK Vest, dated 29.03.2017/20.04.2017). Each patient provided written informed consent prior to enrolling in the study.

\section{Consent for publication}

Not applicable

\section{Availability of data and material}

No additional data are available due to data protection requirements.

\section{Competing interests}

Not applicable

\section{Funding}

This work was supported by The Norwegian Research Council (BEHANDLING, contract no 269855) and the Western Norway Regional Health Authority («Åpen prosjektstøtte») with the Department of Addiction Medicine, Haukeland University Hospital, Bergen, Norway as responsible institution. The funders had no 
role in the study design, data collection and analysis, decision to publish, or preparation of the manuscript. The authors are funded by their respective affiliations.

\section{Authors' contributions}

JHV have led the study design, analysis, and article preparation. EML, CFA, JAS, KAJ, and LTF have contributed in the article preparation. All authors have read and approved the final article.

\section{Acknowledgements}

We thank Nina Elisabeth Eltvik, Christer Kleppe, and Liv Solrunn Mellesdal for their valuable help and input during the planning and preparation phases. We also thank the INTRO-HCV Study Group for important contribution relating to data collection

\section{INTRO-HCV Study Group participating investigators:}

Bergen: Christer Frode Aas, Vibeke Bråthen Buljovcic, Fatemeh Chalabianloo, Jan Tore Daltveit, Silvia Eiken Alpers, Lars T. Fadnes (principal investigator), Trude Fondenes Eriksen, Per Gundersen, Velinda Hille, Kristin Holmelid Håberg, Kjell Arne Johansson, Rafael Alexander Leiva, Siv-Elin Leirvåg Carlsen, Martine Lepsøy Bonnier, Lennart Lorås, Else-Marie Løberg, Mette Hegland Nordbotn, Cathrine Nygård, Maria Olsvold, Christian Ohldieck, Lillian Sivertsen, Hugo Torjussen, Jørn Henrik Vold, Jan-Magnus Økland

Stavanger: Tone Lise Eielsen, Nancy Laura Ortega Maldonado, Ewa Joanna Wilk

proLAR: Ronny Bjørnestad, Ole Jørgen Lygren, Marianne Cook Pierron

Oslo: Olav Dalgard, Håvard Midgard, Svetlana Skurtveit

Bristol: Aaron G. Lim, Peter Vickerman

\section{Authors' information}

Jørn Henrik Vold, MD, PhD, Department of Addiction Medicine and Department of Psychiatry, Haukeland University Hospital, Bergen, Norway and Department of Global Public Health and Primary Care, University of Bergen, Bergen, Norway. Mailing address: Department of Addiction Medicine, Haukeland University Hospital, Jonas Lies vei 65, N-5021 Bergen, Norway. E-mail: jorn.vold@uib.no.

\section{References}

1. Roy A: Characteristics of cocaine dependent patients who attempt suicide. Arch Suicide Res 2009, 13(1):46-51.

2. Roy A: Risk factors for attempting suicide in heroin addicts. Suicide Life Threat Behav 2010, 40(4):416-420. 
3. Roy A, Janal MN: Risk factors for suicide attempts among alcohol dependent patients. Arch Suicide Res 2007, 11(2):211-217.

4. Yuodelis-Flores C, Ries RK: Addiction and suicide: A review. Am J Addict 2015, 24(2):98-104.

5. Mørkved N, Winje D, Dovran A, Arefjord K, Johnsen E, Kroken RA, Anda-Ågotnes LG, Thimm JC, Sinkeviciute I, Rettenbacher $M$ et al: Childhood trauma in schizophrenia spectrum disorders as compared to substance abuse disorders. Psychiatry Res 2018, 261:481-487.

6. The European Union Drug Strategy 2021-25. In. https://data.consilium.europa.eu/doc/document/ST14178-2020-INIT/en/pdf (downloaded May 4, 2021): Euroepan Union; 2020.

7. World Health O: Preventing suicide: a global imperative. Geneva: World Health Organization; 2014.

8. Poorolajal J, Haghtalab T, Farhadi M, Darvishi N: Substance use disorder and risk of suicidal ideation, suicide attempt and suicide death: a meta-analysis. J Public Health (Oxf) 2016, 38(3):e282e291.

9. Santo T, Jr., Clark B, Hickman M, Grebely J, Campbell G, Sordo L, Chen A, Tran LT, Bharat C, Padmanathan P et al: Association of Opioid Agonist Treatment With All-Cause Mortality and Specific Causes of Death Among People With Opioid Dependence: A Systematic Review and Meta-analysis. JAMA Psychiatry 2021, 78(9):979-993.

10. Lawrinson P, Ali R, Buavirat A, Chiamwongpaet S, Dvoryak S, Habrat B, Jie S, Mardiati R, Mokri A, Moskalewicz $\mathrm{J}$ et al: Key findings from the WHO collaborative study on substitution therapy for opioid dependence and HIV/AIDS. Addiction 2008, 103(9):1484-1492.

11. Ward J, Hall W, Mattick RP: Role of maintenance treatment in opioid dependence. Lancet 1999, 353(9148):221-226.

12. Degenhardt L, Bucello C, Mathers B, Briegleb C, Ali H, Hickman M, McLaren J: Mortality among regular or dependent users of heroin and other opioids: a systematic review and meta-analysis of cohort studies. Addiction 2011, 106(1):32-51.

13. Sordo L, Barrio G, Bravo MJ, Indave BI, Degenhardt L, Wiessing L, Ferri M, Pastor-Barriuso R: Mortality risk during and after opioid substitution treatment: systematic review and meta-analysis of cohort studies. Bmj 2017, 357:j1550.

14. Mattick RP, Breen C, Kimber J, Davoli M: Methadone maintenance therapy versus no opioid replacement therapy for opioid dependence. Cochrane Database Syst Rev 2009, 2009(3):Cd002209.

15. Mattick RP, Breen C, Kimber J, Davoli M: Buprenorphine maintenance versus placebo or methadone maintenance for opioid dependence. Cochrane Database Syst Rev 2014(2):Cd002207.

16. Chen VC, Lin TY, Lee CT, Lai TJ, Chen H, Ferri CP, Gossop M: Suicide attempts prior to starting methadone maintenance treatment in Taiwan. Drug Alcohol Depend 2010, 109(1-3):139-143.

17. Degenhardt L, Larney S, Randall D, Burns L, Hall W: Causes of death in a cohort treated for opioid dependence between 1985 and 2005. Addiction 2014, 109(1):90-99.

18. Wilcox HC, Conner KR, Caine ED: Association of alcohol and drug use disorders and completed suicide: an empirical review of cohort studies. Drug Alcohol Depend 2004, 76 Suppl:S11-19. 
19. Darke S, Ross J: Suicide among heroin users: rates, risk factors and methods. Addiction 2002 , 97(11):1383-1394.

20. Comtois KA, Russo JE, Roy-Byrne P, Ries RK: Clinicians' assessments of bipolar disorder and substance abuse as predictors of suicidal behavior in acutely hospitalized psychiatric inpatients. Biol Psychiatry 2004, 56(10):757-763.

21. Elizabeth Sublette M, Carballo JJ, Moreno C, Galfalvy HC, Brent DA, Birmaher B, John Mann J, Oquendo MA: Substance use disorders and suicide attempts in bipolar subtypes. J Psychiatr Res 2009, 43(3):230-238.

22. Pearce LA, Min JE, Piske M, Zhou H, Homayra F, Slaunwhite A, Irvine M, McGowan G, Nosyk B: Opioid agonist treatment and risk of mortality during opioid overdose public health emergency: population based retrospective cohort study. Bmj 2020, 368:m772.

23. McMain S, Ellery M: Screening and Assessment of Personality Disorders in Addiction Treatment Settings. International Journal of Mental Health and Addiction 2008, 6(1):20-31.

24. Comorbidity of substance use and mental disorders in Europe. In. https://www.emcdda.europa.eu/system/files/publications/1988/TDXD15019ENN.pdf (September 3, 2021): European Monitoring Centre for Drug and Drug Addiction; 2015.

25. Brooner RK, King VL, Kidorf M, Schmidt CW, Jr., Bigelow GE: Psychiatric and substance use comorbidity among treatment-seeking opioid abusers. Arch Gen Psychiatry 1997, 54(1):71-80.

26. Ross J, Teesson M, Darke S, Lynskey M, Ali R, Ritter A, Cooke R: The characteristics of heroin users entering treatment: findings from the Australian treatment outcome study (ATOS). Drug Alcohol Rev 2005, 24(5):411-418.

27. Lamont R, Rosic T, Sanger N, Samaan Z: Psychosis and Comorbid Opioid Use Disorder: Characteristics and Outcomes in Opioid Substitution Therapy. Schizophr Bull Open 2020, 1(1):sgaa007.

28. Astals M, Díaz L, Domingo-Salvany A, Martín-Santos R, Bulbena A, Torrens M: Impact of co-occurring psychiatric disorders on retention in a methadone maintenance program: an 18-month follow-up study. Int J Environ Res Public Health 2009, 6(11):2822-2832.

29. Trémeau F, Darreye A, Staner L, Corrêa H, Weibel H, Khidichian F, Macher JP: Suicidality in opioiddependent subjects. Am J Addict 2008, 17(3):187-194.

30. Roy A: Characteristics of opiate dependent patients who attempt suicide. J Clin Psychiatry 2002, 63(5):403-407.

31. Fadnes LT, Aas CF, Vold JH, Ohldieck C, Leiva RA, Chalabianloo F, Skurtveit S, Lygren OJ, Dalgård O, Vickerman $\mathrm{P}$ et al: Integrated treatment of hepatitis $\mathrm{C}$ virus infection among people who inject drugs: study protocol for a randomised controlled trial (INTRO-HCV). BMC Infect Dis 2019, 19(1):943.

32. Nock MK, Borges G, Bromet EJ, Cha CB, Kessler RC, Lee S: Suicide and suicidal behavior. Epidemiol Rev 2008, 30(1):133-154.

33. Dong M, Lu L, Zhang L, Zhang Q, Ungvari GS, Ng CH, Yuan Z, Xiang Y, Wang G, Xiang YT: Prevalence of suicide attempts in bipolar disorder: a systematic review and meta-analysis of observational 
studies. Epidemiol Psychiatr Sci 2019, 29:e63.

34. Cassidy RM, Yang F, Kapczinski F, Passos IC: Risk Factors for Suicidality in Patients With Schizophrenia: A Systematic Review, Meta-analysis, and Meta-regression of 96 Studies. Schizophr Bull 2018, 44(4):787-797.

35. Meltzer HY: Treatment of suicidality in schizophrenia. Ann N Y Acad Sci 2001, 932:44-58; discussion 58-60.

36. John M. Oldham, M.D.: Borderline Personality Disorder and Suicidality. FOCUS 2013, 11(2):277-283.

37. Carrà G, Bartoli F, Crocamo C, Brady KT, Clerici M: Attempted suicide in people with co-occurring bipolar and substance use disorders: systematic review and meta-analysis. J Affect Disord 2014, 167:125-135.

38. Popovic D, Benabarre A, Crespo JM, Goikolea JM, González-Pinto A, Gutiérrez-Rojas L, Montes JM, Vieta E: Risk factors for suicide in schizophrenia: systematic review and clinical recommendations. Acta Psychiatr Scand 2014, 130(6):418-426.

39. Kolla NJ, Eisenberg H, Links PS: Epidemiology, risk factors, and psychopharmacological management of suicidal behavior in borderline personality disorder. Arch Suicide Res 2008, 12(1):119.

40. Davis L, Uezato A, Newell JM, Frazier E: Major depression and comorbid substance use disorders. Curr Opin Psychiatry 2008, 21(1):14-18.

41. Lobmaier P, Skeie I, Lillevold P, Waal H, Bussesund K, Clausen T: The Norwegian OAT report 2020 (LAR statusrapport 2020 - LAR behandling under første året med COVID-19 pandemi). In. https://www.med.uio.no/klinmed/forskning/sentre/seraf/publikasjoner/rapporter/2020/serafrapport-nr-1-2020-statusrapport-2019.pdf (September 10, 2021): The Norwegian Centre for Addiction Research (Norwegian: Senter for rus- og avhengighetsforskning (SERAF)); 2021.

42. Degenhardt L, Hall W: Extent of illicit drug use and dependence, and their contribution to the global burden of disease. Lancet 2012, 379(9810):55-70.

43. Marshall EJ: Adolescent alcohol use: risks and consequences. Alcohol Alcohol 2014, 49(2):160-164.

44. Poudel A, Gautam S: Age of onset of substance use and psychosocial problems among individuals with substance use disorders. BMC Psychiatry 2017, 17(1):10.

45. Fergusson DM, Boden JM: Cannabis use and later life outcomes. Addiction 2008, 103(6):969-976; discussion 977-968.

46. Odgers CL, Caspi A, Nagin DS, Piquero AR, Slutske WS, Milne BJ, Dickson N, Poulton R, Moffitt TE: Is it important to prevent early exposure to drugs and alcohol among adolescents? Psychol Sci 2008, 19(10):1037-1044.

47. Trull TJ, Freeman LK, Vebares TJ, Choate AM, Helle AC, Wycoff AM: Borderline personality disorder and substance use disorders: an updated review. Borderline Personal Disord Emot Dysregul 2018, 5:15.

48. Hawton K, van Heeringen K: Suicide. Lancet 2009, 373(9672):1372-1381. 
49. Klonsky ED, May AM, Saffer BY: Suicide, Suicide Attempts, and Suicidal Ideation. Annu Rev Clin Psychol 2016, 12:307-330.

50. Ferrari AJ, Norman RE, Freedman G, Baxter AJ, Pirkis JE, Harris MG, Page A, Carnahan E, Degenhardt L, Vos $T$ et al: The burden attributable to mental and substance use disorders as risk factors for suicide: findings from the Global Burden of Disease Study 2010. PLoS One 2014, 9(4):e91936.

51. Schneider B: Substance Use Disorders and Risk for Completed Suicide. Archives of Suicide Research 2009, 13(4):303-316.

52. Oquendo MA, Volkow ND: Suicide: A Silent Contributor to Opioid-Overdose Deaths. N Engl J Med 2018, 378(17):1567-1569.

53. Dasgupta N, Funk MJ, Proescholdbell S, Hirsch A, RibisI KM, Marshall S: Cohort Study of the Impact of High-Dose Opioid Analgesics on Overdose Mortality. Pain Med 2016, 17(1):85-98.

54. Multiple Cause of Death 1999-2019 on CDC WONDER Online Database. In., vol. Data are from the Multiple Cause of Death Files, 1999-2019, as compiled from data provided by the 57 vital statistics jurisdictions through the Vital Statistics Cooperative Program. Accessed at http://wonder.cdc.gov/mcd-icd10.html (access date: September 16, 2021): Centers for Disease Control and Prevention, National Center for Health Statistics; 2020.

\section{Tables}

Table 1: Basic characteristics of 595 opioid agonist therapy patients (numbers (n) and percentages (\%)): 
All patients

$(\mathrm{N}=595)$

Age (years), $n(\%)$

$18-30$

$30-40$

$40-50$

$50-60$

$\geq 60$

Mean (SD)
$57(10)$

169 (28)

$193(32)$

$10(23)$

$36(6)$

$44(10)$

Gender, $n$ (\%)

Male

$420(71)$

Female

$175(29)$

Highest level of education, $n(\%)$

Not completed primary school

$30(5)$

Completed primary school (9 years)

$266(45)$

Completed high school (12 years)

$243(41)$

$\leq 3$ years of college or university

$46(8)$

$>3$ years of college or university

$10(2)$

Injected substances the past 30 days, $\mathrm{n}(\%)$

$181(30)$

Unstable housing the past 30 days $^{1}{ }^{1)}, \mathrm{n}(\%)$

$58(10)$

Substances used the past 30 days $^{2)}, \mathrm{n}(\%)$

Cannabis

$396(67)$

Benzodiazepines

$354(60)$ 


\begin{tabular}{ll}
\hline Alcohol & $349(59)$ \\
\hline Amphetamines & $249(42)$ \\
\hline Opioids & $123(21)$ \\
\hline Cocaine & $25(4)$ \\
\hline Mean age for the onset of substance use (mean (SD)) & $13(2)$ \\
\hline Comorbidities, $\mathrm{n}(\%)$ & \\
\hline Hepatitis C virus infection & $350(59)$ \\
\hline Hepatitis B virus infection & $<5(<1)$ \\
\hline Human immunodeficiency virus & $<5(<1)$
\end{tabular}

SD: Standard deviation.

1) An unstable housing was defined as living in a homeless shelter or with family or friends at any time during the 30 days leading up to the health assessment. Having owned or rented housing situation or being imprisoned were defined as a stable housing.

2) The number of patients who have used substances at least once during the 30 days leading up to the health assessment.

Due to technical limitations, table 2,3 is only available as a download in the Supplemental Files section.

Figures 


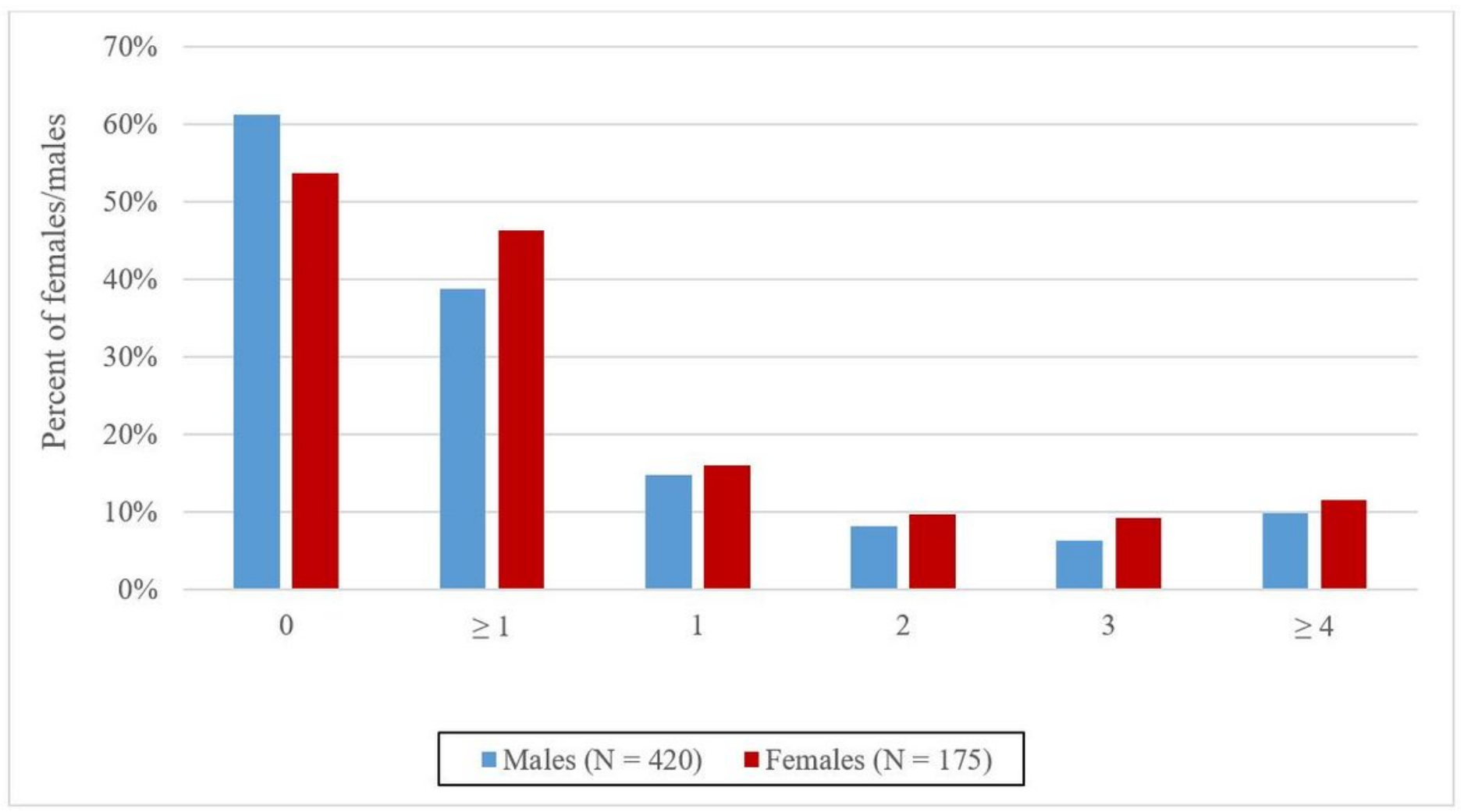

\section{Figure 1}

The number of suicide attempts among patients enrolled in opioid agonist therapy. Legends: OAT: Opioid agonist therapy. The figure displays the number of OAT patients who have attempted zero, one, two, three, and four or more suicide attempts during their lifetime.

\section{Supplementary Files}

This is a list of supplementary files associated with this preprint. Click to download.

- Table2.xlsx

- Table3.xlsx 